\title{
Writing Errors Among Arab EFL Learners: A Review of Literature
}

\author{
Aseel Altheneyan \\ College of Arts, King Saud University, Saudi Arabia
}

Nora F. Boayrid (Corresponding author)

College of Arts, King Saud University, Saudi Arabia

E-mail: nfboayrid@iau.edu.sa

Received: August 19, 2019

Accepted: October 6, 2019

Published: October 30, 2019

doi:10.5296/ijl.v11i5.15294

URL: https://doi.org/10.5296/ij1.v11i5.15294

\begin{abstract}
The aim of this article is to provide an overview of common writing errors among Arab learners of English as a second language by analyzing the findings of 15 studies. The negative influence of the first language (L1) is called interference and was first introduced by Lado (1957). This article focused on studies that have examined the negative influence of Arabic on the English writing of Arab learners. It has excluded studies that dealt with common errors resulting from different sources such as, intra-lingual errors (i.e. resulting from L2). The findings of the reviewed studies were analyzed based on James's (2013) error taxonomy. Accordingly, three types of errors were identified, namely, substance errors, textual errors, and discourse errors. The analysis suggested that Arabic has influenced learners' English writings at multiple levels.
\end{abstract}

Keywords: Arabic language, Error analysis, Interference, L2 writing errors, Negative transfer

\section{Introduction}

Many researchers believe that transfer from the mother tongue while leaning a second language is inevitable (Lado, 1957; Ellis, 1990). Transfer from the learner's L1 to the learner's L2 is called language interference first introduced by Lado (1957). Interference was defined by Dulay (1982) as the habitual automatic transfer of surface structures from the native language into the surface of the target language. Odlin (1989) states that "transfer is the influence resulting from similarities and differences between the target language and any other language 
that has been previously acquired" (p. 27). Language interference was classified by Gass and Selinker (1983) into two types: negative and positive. Positive transfer occurs when two linguistic features are similar in the two languages (Irujo, 1986). Negative transfer, however, results from two linguistic features being different in the two languages leading to difficulties in learning and, thus, becoming error inducing (Lado, 1964). According to Corder (1986), errors are deviant forms that are different from those produced by native speakers of the target language and are reflective of learners' knowledge; thus, they cannot be corrected by the learners. Gass and Selinker (2008) state that errors are "red flags" (p. 102) that are evidence of the learners' lack of knowledge. Mistakes, unlike errors, lack systematicity, they are a problem of production, not knowledge (Corder, 1976). Corder (1976) also states that the significance of errors stems from their ability to provide researchers with evidence on the manner in which language is learned and acquired in addition to the strategies employed by learners to learn the target language. Contrastive Analysis Hypothesis ( $\mathrm{CAH}$ ) claims that errors in the second language can be predicted and identified by comparing and contrasting the systems of two languages and identifying the differences (Wardhaugh, 1970). CAH was criticized from two main perspectives: First, its failure to account for and predict all the difficulties faced by learners (Ellis \& Ellis, 1994). Second, CAH predicts many difficulties that are not observed in second language learning (Odlin, 1989). Thus, the concept of CAH was weakened into Cross-Linguistic Influence (Odlin, 2003). Gass and Selinker (2008) describe the 'weak' version as "it begins with what learners do and then attempts to account for those errors on the basis of NL-TL differences" (p. 97); therefore, CAH becomes a part of Error Analysis (EA). EA, according to Richards \& Schmidt (2002) is the study and analysis of errors made by second language learners. Brown (2014) defined EA in detail as the process in which deviations from the rules of the second language are observed, analyzed, and classified in order to reveal the system operated by the learner. EA is more comprehensive than CA because the latter only relates errors to the native language while EA classifies errors into inter-lingual and intra-lingual errors (Gass \& Selinker, 2008). Inter-lingual errors result from L1 transfer (Corder, 1971). Intra-lingual errors, however, come from the target language, also called developmental errors (Gass \& Selinker, 2008). This research aims to investigate the inter-lingual errors made by Arab learners of English in writing analyzed and reported in 15 studies. The errors are classified and structured in the literature according to James (2013) Error Taxonomy as follows: substance errors, textual errors, and discourse errors.

\section{Analysis}

\subsection{Substance Errors}

Substance errors are errors done when operating the phonological or the graphological substance systems (James, 2013). Such errors deal with mechanics such as spelling, punctuation, and capitalization.

\subsubsection{Spelling}

Abu-Rabia and Sammour (2013) state that "successful English spelling performance involves the processes of segmenting the spoken word into its phonemic components and then selecting the appropriate graphemes to represent the phonemes" (p. 19). Numerous spelling errors made 
by Arab learners of English have been attributed to the Arabic language. Haggan (1991) stated that the difficulty in English spelling for Arab learners can be traced back to two reasons. The first is the difference in the scripts of English and Arabic. The second is that Arabic has pronunciation-based spelling while English does not. Al-Jarf (2010) clarifies that Arabic has "a one to one correspondence between phonemes (spoken sounds) and graphemes (written symbols)" (p.13), thus, Arabic has no double letters, very few silent letters and no consonant and vowel diagraph. As a result, Arab learner make pronunciation-based spelling errors such as the omission of the silent letter ' $\mathrm{K}$ ' in the word knife, nife. They also make substitution errors of letters, for example, they were found to substitute the letter ' $S$ ' for ' $Z$ ' in writing the word busy; following the pronunciation of the word /'brz.i/, bezy.

Mahmoud (2013) identified three types of pronunciation-based errors. The first type results from the absence of certain phonemes $(/ \mathrm{p} /, / \mathrm{v} /, / \mathrm{t} \mathrm{f} /, / 3 /)$ in the native language leading to their replacement with the phonemes $(/ \mathrm{b} /, / \mathrm{f} /, / \mathrm{J} /, / \mathrm{d} /)$ respectively due to mispronunciation-based substitution. This confirms the claim by Allaith and Joshi (2011) that L1 phonology has a great impact on L2 English spelling. Examples of spelling errors include, writing lifes instead of lives, and cabable instead of capable.

The second type of errors are due to consonant clusters, which are problematic for Arab learners, since they are uncommon in Arabic. Thus, learners tend to insert vowels to facilitate pronunciation. Hence, making vowel-addition spelling errors, such as the insertion of the letter ' $\mathrm{E}$ ' in belonges, and the insertion of the letter ' $\mathrm{U}$ ' in multipule.

The third type of pronunciation-based errors occurs due to the Arabic pronunciation of English words borrowed from Arabic, such as badawin instead of bedouin, and gazal instead of gazelle. Arabic words borrowed from English are also erroneous such as bas instead of bus.

\subsubsection{Capitalization}

Capitalization is an important feature in the English language writing that facilitates the readability of the text (Ritter, 2002). Sawalmeh (2013) analyzed essays written by Arab learners and found that most of the capitalization errors made are due to Arabic interference. Such errors mainly result from the different writing system of English and Arabic according to Almurshedi (2014). The two most common errors made are wrongful capitalization of letters and wrongful non-capitalization of others in addition to the malformation of letters (Ababneh, 2017). He clarifies that former occurs as a result if the absence of the concept of capitalization in the Arabic language. Thus, resulting in the non- capitalization of words in the beginning of the sentence, proper nouns, names of cities ... etc. The latter takes place as a result of the lack of distinction between upper- and lower-case letters in Arabic, resulting in learners randomly capitalizing letters.

\subsubsection{Punctuation}

English and Arabic have vastly different punctuation systems. This leads learners to make many mistakes in English punctuation as Arabic punctuation is simpler and less restrictive. Mustafa (2017) found that Arab learners made numerous omission errors in punctuation especially full stops. Omission of full stops can be attributed to the length of Arabic sentences. 


\section{Macrothink}

International Journal of Linguistics

ISSN 1948-5425

2019, Vol. 11, No. 5

It is common in Arabic to use only one or two full stops in one paragraph and separate sentences by using commas. English on the other hand, necessitates the use of a full stop after a complete sentence. Thus, Arab learners use full stops according to the Arabic punctuation rules. In addition, Abisamra (2003) found that the most persistent punctuation error resulting from Arabic interference is the omission of commas. Such errors result from the difference in commas usage in English versus Arabic. English requires the use of a comma in many sentences that Arabic does not (Abisamra, 2003), such as:

1. Between a fronted subordinate or conditional clause and the main sentence

When I get to university $\boldsymbol{\nabla}$ I will try my best to get high honors in architecture.

2. Before and, but, or, nor, for, so, and yet, when they join independent clauses.

I don't just want to be a parent $\mathbf{\nabla}$ but a mom who is proud and deserves that position.

3. Between items in a series (Mohamed \& Omar, 1999).

I went to the cafe and I bought two cookies and a coffee and a muffin.

\subsection{Textual Errors}

James (2013) stated that the term text refers to any instance of application of encoding rules in lexico-grammar. Text errors occur due to the misapplication of lexico-grammar rules to achieve a texture (James, 2013).

\subsubsection{Lexical Errors}

Diab (1996) and Abisamra (2003) found that lexical errors committed by Arab learners of English are mainly semantic errors that stem from direct translation of the Arabic word. Thus, learners choose the wrong equivalent for the word which is mostly a near synonym such as *Animals are afraid of high sounds.

Learners use of the word 'high' instead of 'loud' is the result of literal translation of the Arabic word 'aliah' (Abisamra, 2003). Such miss-selection may also result from one Arabic word having two distinctive meanings in English such as the word maktaba which can mean both 'bookstore' and 'library', thus, leading learners to commit errors like the following:

*The patient went to a special hospital.

*My mother holds a private place in my heart.

These errors occurred because 'private' and 'special' have one equivalent in Arabic which is 'khas' (Diab, 1996). Diab (1996) adds that such miss-selection errors lead to collocational errors in Arab learners writing.

\subsubsection{Grammatical Errors}

Based on James' (2013) classification of errors, errors in grammar comprise errors in morphology and syntax. Morphology deals with the structure of word unit and syntax deals with the structure of texts larger than words such as sentences (James, 2013). Errors in 
morphology should not be confused with ones in the lexical level; while both are in the level of words, errors in morphology is only concerned with the failure to supply any part of English word classes (e.g. nouns and verbs) with the needed morpheme. For instance, *six book instead of six books indicates an error in morphology. Atashian and Al-Bahri (2018) suggested that errors in grammar are frequent second language writings. In line with this, the following subsections deal with common grammatical errors found in the writings of Arab EFL learners that are the result of negative Arabic transfer.

\subsubsection{Agreement}

Diab (1996) analyzed the English writings of Lebanese students, his findings revealed that out of 558 grammatical errors, 75 of them were in agreement. The students seem to have a problem with adjectives/adverbs agreeing with the nouns they modify as in the following examples:

*My sister goes to others shops.

*The art of paragraphs writings.

Diab (1996) explained that this confusion results from the negative transfer of Arabic rules. In Arabic, adjectives agree in numbers with the modified nouns, whereas in English, adjectives modifying nouns are usually singular.

\subsubsection{Articles}

Ridha (2012), Abu Rass (2015), Sabbah (2016), and Shukri (2014) found that Arab learners have errors in using English articles correctly. The studies found that Arab learners tend to overuse the definite article 'the' as in the following examples:

*The marriage is a holy ceremony.

*The persistence is necessary for the success.

Errors in using definite article 'the' are attributed to their first language influence, Arabic. In Arabic, abstract nouns are preceded with definite article 'al' = 'the'. English language, however, does not add a definite article before abstract words.

In addition, Shukri (2014) found that out of 282 errors in Saudi EFL learners, 75 were in omitting indefinite articles as in *is big family. Shukri (2014) explained that the omission of indefinite articles is the result of Arabic negative transfer since the Arabic language has no indefinite articles.

\subsubsection{Prepositions}

Scott and Tucker (1974) illustrated that English prepositions are difficult for second language learners; since in English, different prepositions can serve the same function such as 'to' and 'for'. Ridha (2012) found that Lebanese learners when confused what preposition to choose, they compare them to the Arabic language which results in errors as in *He is ready to the exam instead of He is ready for the exam. 
Scott and Tucker (1974) explained, "prepositions seldom have a one to one correspondence between English and Arabic. An Arabic preposition may be translated by several English prepositions, while an English usage may have several Arabic translations” (p. 85).

\subsubsection{Plural Nouns}

Ridha (2012) has found that EFL Arab learners tend to pluralize uncountable nouns in English language; this is possible because, in Arabic, there are no uncountable nouns. An Arab learner made the following error, *Statistics are often carried out to determine the increase in population. The word statistics has confused the student not only because it ends with the letter ' $\mathrm{S}$ ', but the word is plural in Arabic.

\subsubsection{Word Order}

Abu Rass (2015) found that students tend to follow the sentence structure of their first language when writing in English. Hence, they produce structures that resemble the Arabic structure (VSO) as in a sentence written by an Arab student *Was the accident a disaster.

Ridha (2012) and Abu Rass (2015) also found that Arab learners have problems with the place of noun modifiers as in the following examples:

*Every person almost has a car.

\section{*I read many books difficult.}

The errors are attributed to Arabic negative transfer as adjectives, in Arabic, follow the nouns they modify.

\subsubsection{Coordination}

Ridha (2012) suggested that Arab learners have a problem with using the coordination 'and'; they tend to follow Arabic rules in which the coordination 'and' is placed after each item in a list of items. Ridha (2012) found this type of errors in Arab learner writing as in this example,

My favorite fruits are cherries and peaches and pears and watermelons.

\subsubsection{Pronouns}

Abu Rass (2015) found that Arab students tend to avoid using the pronoun 'it' because it has no equivalent in Arabic. He as well found that they tend to use verbs with embedded pronouns as in *After 3 years of marriage, have been facing pressure from their family. Abu Rass (2015) attributed this to the Arabic rules which allow for embedded pronouns.

\subsection{Discourse Errors}

The last category of James' (2013) classification of interlanguage errors is discourse errors. The category is based on Bhatia's (1974) analysis of written compositions by second language learners. She focused on the organization and development of paragraphs; specifically, she analyzed writing qualities such as relevance, clarity, development, and originality. James (2013) labeled her work to be concerned with the coherence of learner writing. Coherence is defined "in terms of communicative function, involving the writer's intention and the reader's 
interpretation" (James, 2013, p. 161). In this regard, the negative transfer of Arabic rules was found in the literature on writing errors by Arab learners. The Arabic style, which is characterized by being indirect, personal, and emotional has an influential role in their discourse errors at multiple levels. The following subsections deal with problems resulting in this area:

\subsubsection{Relevance}

Errors in relevancy are the least frequent in the literature, in fact, it has only accounted for $4.18 \%$ of errors committed by Arab students in Murad and Khalil's (2015) study. Murad and Khalil (2015) explained that this type of error is attributed to the Arabic style, which celebrates amplification.

\subsubsection{Clarity}

Abu Rass (2015) suggested that Arab learners tend to write in a vague manner assuming that readers are aware of their intentions as in *The things that people around the world face. This writing style is attributed to the Arabic language which encourages being implicit and indirect (Abu Rass, 2015).

\subsubsection{Development}

Some studies found that Arab learners face difficulties in writing well-organized essays in English (e.g. Abu Rass, 2015; Ahmed, 2010; Murad \& Khalil, 2015). Followings are examples of topic sentences written by Arab learners:

I believe that watching movies really benefits us with many aspects of our lives.

We all agree that sometimes the government makes bad laws and policies.

English topic sentences are supposed to be direct and formal, the examples above, however, are characterized by being personal and indirect which show the influence of the Arabic language (Abu Rass, 2015). Likewise, in writing argumentative essays, Arab learners tend to argue by "repeating arguments, paraphrasing them and doubling them" (Koch, 1083, p. 500, as cited in Abu Rass, 2015); which means that they follow the style of the Arabic language that uses such techniques to emphasis as in the following example found in Abu Rass' (2015) study:

It is incredible that we can learn about the other cultures, the things the people around the world face, their thinking ways and also their lifestyle when they are immigrants and out of their country.

\subsubsection{Originality}

Abu Rass (2011) analyzed six free journals written by Arab English trainees. His findings suggested that the Islamic culture of Arabs has an impact on the origin of their ideas. Abu Rass (2011) has encountered the following sentences written by the participants:

I will get a very big treasure of knowledge from all of the teachers.

Very suitable for me and other students as Arabs. 
Abu Rass (2011) proposed that the two examples show the influence of the Islamic culture on the learners; in Islam, we are expected to gain knowledge and wisdom from the elderly people. Likewise, the second example shows a tendency towards group-orientation that is largely the influence of Islamic culture, which celebrates unity.

\section{Conclusion}

This study aimed to identify the most problematic areas in the writings of Arab learners where the negative transfer occurs. Arabic language interference was found in many aspects of Arab learners writing. Inter-lingual errors were found in substance, text, and discourse. Substance errors included spelling punctuation and capitalization errors. Spelling errors in Arab learners' writings were mostly due to pronunciation. These pronunciation-based spelling errors are the result of Arabic having a pronunciation-based spelling while English does not. Capitalization errors, on the other hand, were attributed to English and Arabic using different scripts and the latter's lack of distinction between upper and lower case. Numerous punctuation errors were also found, which were mostly the omission of commas and full stops. These errors are because of Arabic and English's different punctuation rules. Textual errors made by Arab learners were present in both lexicon and syntax. Lexical errors occurred due to the direct translation from Arabic with no attention to English collocations. Syntactical errors, however, encompass different types of errors in agreement, articles, preposition, plural nouns, word order, coordination, and pronouns. These errors result from the vastly different grammars of English and Arabic. Finally, numerous discourse errors were identified within Arab learners writing. These errors are a result of stylistic differences between Arabic and English with the earlier being indirect, personal, redundant and originality lacking, which contradicts with English language style. This investigation is not merely to shed light on these errors but also to aid teachers in expecting where their learners are weakest. Teachers' awareness about such errors will aid in the instruction of the lesson by tailoring the lesson according to the learner's needs and highlighting the differences between English and Arabic that might be indistinguishable to the learners. This paper focused mainly on writing errors committed by Arabs, further studies can be carried out to investigate other types of errors made by learners and/or positive transfer of Arabic to English.

\section{References}

Ababneh, I. (2017). Analysis of written English: The case of female university students in Saudi Arabia. International Journal of Social Science Studies, 5(4), 1-5. https://doi.org/10.11114/ijsss.v5i4.2264

Abisamra, N. (2003). An analysis of errors in Arabic speakers' English writings. Investigating writing problems among Palestinian students studying English as a foreign language. Unpublished doctoral dissertation.

Abu Rass, R. (2011). Cultural transfer as an obstacle for writing well in English: The case of Arabic speakers writing in English. English Language Teaching, 4(2), 206-212. https://doi.org/10.5539/elt.v4n2p206 


\section{I Macrothink}

International Journal of Linguistics

ISSN 1948-5425

2019, Vol. 11, No. 5

Abu Rass, R. (2015). Challenges face Arab students in writing well-developed paragraphs in English. English Language Teaching, 8(10), 49-59.

Abu-Rabia, S., \& Sammour, R. (2013). Spelling errors' analysis of regular and dyslexic bilingual Arabic-English students. Open Journal of Modern Linguistics, 3(1), 58-68. https://doi.org/10.4236/ojml.2013.31007

Ahmed, A. (2010). Students' problems with cohesion and coherence in EFL essay writing in Egypt: Different perspectives. Literacy Information and Computer Education Journal (LICEJ), 1(4), 211-221. https://doi.org/10.20533/licej.2040.2589.2010.0030

Al-Jarf, R. (2010). Spelling error corpora in EFL. Sino-US English Teaching, 7(1), 6-15.

Allaith, A., \& Joshi, M. (2011). Spelling performance of English consonants among students whose first language is Arabic. Reading and Writing, 24(9), 1089-1110. https://doi.org/10.1007/s11145-010-9294-3

Almurshedi, G. (2014). Subject-verb agreement grammatical errors and punctuation: Errors in submissions of male UAE university students. European Journal of Business and Innovation Research, 2(5), 44-47.

Atashian, S., \& Al-Bahri, K. (2018). Towards Arab students' grammatical errors in academic writing \& their perceptions. Arab World English Journal (AWEJ), 140-145. https://dx.doi.org/10.24093/awej/MEC1.10

Bhatia, T. (1974). An error analysis of students' compositions. IRAL: International Review of Applied Linguistics in Language Teaching, 12(4), 337.

Brown, D. (2014). Principles of language learning and teaching: A course in second language acquisition. White Plains, NY: Pearson Education.

Corder, P. (1971). Idiosyncratic dialects and error analysis. IRAL: International Review of Applied Linguistics in Language Teaching, 9(2), 147-160. https://doi.org/10.1515/iral.1971.9.2.147

Corder, P. (1976). The Significance of Learner"es Errors. 1RAL: International Review of Applied Linguistics in Language Teaching, 5, 161-170. https://doi.org/10.1515/iral.1967.5.1-4.161

Corder, P. (1986). Error analysis and inter-language. Oxford: Oxford University Press.

Diab, N. (1996). The transfer of Arabic in the English writings of Lebanese students. The ESPecialist, 18(1), 71-83.

Dulay, H. (1982). Language Two. Oxford University Press, NY.

Ellis, R. (1990). Understanding second language acquisition. Oxford: Oxford University Press.

Ellis, R., \& Ellis, R. (1994). The study of second language acquisition. Oxford University. 


\section{Macrothink}

International Journal of Linguistics

ISSN 1948-5425

2019, Vol. 11, No. 5

Gass, M., \& Selinker, L. (1983). Language transfer in language learning. Issues in second language research. Newbury House Publishers, Inc., Rowley.

Gass, S., \& Selinker, L. (2008). Second language acquisition: An introductory course (3rd ed.). New York: Routledge/Taylor Francis. https://doi.org/10.4324/9780203932841

Haggan, M. (1991). Spelling errors in native Arabic-speaking English majors: A comparison between remedial students and fourth year students. System, 19(1-2), 45-61. https://doi.org/10.1016/0346-251X(91)90007-C

Irujo, S. (1986). Don't put your leg in your mouth: Transfer in the acquisition of idioms in a second language. Tesol Quarterly, 20(2), 287-304. https://doi.org/10.2307/3586545

James, C. (2013). Errors in language learning and use: Exploring error analysis. London: Routledge. https://doi.org/10.4324/9781315842912

Lado, R. (1957). Linguistics across cultures: Applied linguistics for language teachers.

Lado, R. (1964). Linguistics across cultures. Ann Arbor.

Mahmoud, A. (2013). Spelling errors of Arab learners of EFL: A two-way analysis. TESOL Arabia Perspectives, 20(1), 6-12.

Mohamed, A., \& Omar, M. (1999). Syntax as a marker of rhetorical organization in written texts: Arabic and English. IRAL: International Review of Applied Linguistics in Language Teaching, 37(4), 291-305.

Murad, M., \& Khalil, H. (2015). Analysis of errors in English writings committed by Arab first-year college students of EFL in Israel. Journal of Language Teaching and Research, 6(3), 475-481. https://doi.org/10.17507/jltr.0603.02

Mustafa, A. (2017) Syntactic errors Arab learners commit in writing. Journal of Language, Linguistics and Literature, 3(1), 1-7.

Odlin, T. (1989). Language transfer: Cross-linguistic influence in language learning. Cambridge University Press. https://doi.org/10.1017/CBO9781139524537

Odlin, T. (2003). Cross-Linguistic Influence. The Handbook of Second Language Acquisition, 436-486.

Richards, C., \& Schmidt, R. (2002). Longman dictionary of language teaching and applied linguistics. New York: Longman.

Ridha, N. (2012). The effect of EFL learners' mother tongue on their writings in English: An error analysis study. $A D A B A L-B A S R A H,(60), 22-45$.

Ritter, M. (2002). The Oxford Guide to Style. Oxford: Oxford University Press.

Sabbah, S. (2016). Negative transfer: Arabic language interference to learning English. Arab World English Journal (AWEJ), 4, 269-288. https://doi.org/10.2139/ssrn.2844015 


\section{Macrothink}

International Journal of Linguistics

ISSN 1948-5425 2019, Vol. 11, No. 5

Sawalmeh, M. (2013). Error analysis of written English essays: The case of students of the preparatory year program in Saudi Arabia. English for Specific Purposes World, 40(14), 1-17.

Scott, S., \& Tucker, R. (1974). Error Analysis and English-language strategies of Arab students 1. Language Learning, 24(1), 69-97. https://doi.org/10.1111/j.1467-1770.1974.tb00236.x

Shukri, A. (2014). Second language writing and culture: Issues and challenges from the Saudi learners' perspective. Arab World English Journal (AWEJ), 5(3), 190-207.

Wardhaugh, R. (1970). The contrastive analysis hypothesis. TESOL Quarterly, 4(2), 123-130. https://doi.org/10.2307/3586182

\section{Copyrights}

Copyright for this article is retained by the author(s), with first publication rights granted to the journal.

This is an open-access article distributed under the terms and conditions of the Creative Commons Attribution license (http://creativecommons.org/licenses/by/4.0/) 